\title{
Impact of Vehicular Emissions on Environment in and Around Chennai City-Assessment and Control Measures
}

\author{
A.Mani , G.Kannan
}

\begin{abstract}
Abstract: Air quality emergency in urban areas is for the most part because of vehicular emanations. Transportation frameworks are expanding all over the place and the enhancements in innovation are deficient to balance development. Expanding urbanization, Industrialization and mechanization in India is answerable for more elevated levels of contamination. Engine vehicle discharges as of now include a significant wellspring of air contamination in Indian urban areas. They are evaluated to be liable for 60 to $70 \%$ of the air contamination in the greater part of the urban communities. Engine vehicle emanations influences the wellbeing of all pay gatherings yet it's effect on the poor is essentially high because of their working and living in open places.In a large portion of the Indian urban areas, the contamination loads are far above satisfactory levels and Delhi has gained the questionable qualification of being the second most dirtied city on the planet and Chennai city is gradually approaching the second position alongside Delhi, in Indian setting, according to the report.
\end{abstract}

Henceforth a reality discovering overview was led to survey the contamination worry in different areas of the Chennai city covering Residential, Industrial and Commercial territory. A portion of the key pollutants(PM 2.5 and PM10) are in abundance of allowed levels and the issues have arrived at undermining dimensions.To decrease the vehicular emanations, it is important to structure and actualize idiot proof procedures and to execute contamination control gauges adequately to control discharges.

Key words : Air pollution, PM10, Vehicular pollution,

\section{INTRODUCTION}

Human activities generate three sources of air pollution: stationary or point, mobile, and indoor. In developing countries especially in the rural area, indoor air pollution from using open fires for cooking and heating may be a serious problem. Industries, power plants etc. are the cause of stationary air pollution. But in urban areas - both developing and developed countries, it is predominantly mobile or vehicular pollution that contributes to overall air quality problem. Increasing urbanization, Industrialization and motorization in India is responsible for higher levels of pollution. Transportation systems are increasing everywhere and the improvements in technology are insufficient to counteract growth. Motor vehicle emissions already comprise a major source of air pollution in Indian cities. They

Revised Manuscript Received on October 22, 2019.

Dr.A.Mani, Professor, Department Of Civil Engineering,,Bharath Institution Of Higher Education And Research,TamilNadu, India Email: maniathi57@yahoo.in

G.Kannan, PG Student,Department Of Environmental Engineering,,Bharath Institution Of Higher Education And Research,TamilNadu, India . Email: kannang99@gmail.com are estimated to be responsible for 60 to $70 \%$ of the air pollution in most of the cities. In most of the Indian cities, the pollution loads are far above acceptable levels and threaten human health and quality of life.. Motor vehicle emissions affects the health of all income groups but it's impact on the poor is significantly high due to their working and living in open places.[1]-[6]

Source apportionment contribution of vehicles to pollution:

Pollutants in the ambient air are contributed by many sources of which vehicles are one. The contributions of vehicular emissions to ambient air quality depends on the engine type, traffic movements, fuel quality etc. Two stroke engine two and three wheelers and diesel vehicles are the major sources of particulate matter. Gasoline cars produce more of carbon monoxide. More of particulates and Sox in the vehicle exhaust in Delhi may be due to larger number of two and three wheelers and buses compared to Mumbai. Similarly larger amounts of carbon monoxide in Mumbai may be due to larger share of gasoline cars in Mumbai compared to Delhi. Available evidence indicate that the pollutants with the most damaging health impacts are fine particulate matter(PM2.5 causing serious respiratory illness and premature death). In most of the Indian cities, two stroke engine two and three wheelers and diesel vehicles are the major sources of particulates especially fine particles. Studies indicate that though vehicles are responsible for about 16 to $20 \%$ of the fine particulate matter, they are responsible for 60 to $70 \%$ of the fine particulates. Pollution abatement from vehicles therefore is likely to be a key part of urban air quality management strategies in most of the Indian cities.[7]-[12]

Urbanization:

India is one of the largest developing country and its economic expansion over the past decades has been one of the strongest in the world history. Such an economic expansion increases uses of fossil fuels and automobile emission. Increasing urbanization, industrialization, and motorization result in more energy demand which generally lead to higher emissions of air pollutants, the Indian population is fast urbanizing. Out of about one billion population in 2000, the urban population was around 300 million,(30\%) 410 million in $2010(36 \%)$ and it is expected to reach $44 \%$ by 2020 .

Apart from increased industrialization in urban areas, frequent droughts and unequal land tenure system have affected the rural poor significantly and resulted in their migration to large cities in India in the last two decades. 
Although jobs in urban areas may not pay well, they provided higher living standards than could be obtained in rural areas. As a result, there were massive population movements from rural areas to cities, especially mega cities with more than four million population. These changes have exacerbated the demand for transport per capita trip rates and trip lengths.[13]-[17]

\section{Motor vehicle population trends:}

The incomparable Indian dream is to claim a vehicle more as a grown-up toy. This fantasy is turning into a simple reality .Thanks to expanding individual wages, merciful financing plans and the administration approach to energize vehicle industry. In India monetary development during 1990s has set off a blast in the number and utilization of engine vehicles. Till 1982 just three producers M/s.Hundustan Motors. M/s.Premier Automobiles and M/s. Standard Motors rented the engine vehicle division. Inferable from low volumes, it propagated old advances. In 1982, Maruthi Udyog Ltd. Came up as an administration activity in a joint effort with Suzuki of Japan to set up volume creation of contemporary models. Subsequent to lifting of authorizing in 1990s, 17 new pursuits have come up of which 16 are makers of vehicles. Correspondingly there are 14 two/three wheeler produces. The no. of vehicles made and advertised in India during the most recent 15 years is shown in Table. It tends to be seen that the engine vehicle armada expanded from 0.30 million of every 1951 to more than 50 million out of 2001 and 150 million out of 2015. The portion of bike armada was $9 \%$ in 1951 and increment to over $80 \%$ by 2001 .The portion of transports declined from $11 \%$ in 1951 to under $1 \%$ by 2001[17]-[22]

\section{VEHICLE POLLUTION : AN ANALYSIS:}

Total emissions from a vehicle during a period consists of emissions per km multiplied by the total vehicle kms (VKT) by the vehicle during that period. Hence the two major ways of reducing vehicular emissions are reducing the emissions per $\mathrm{km}$ and reducing the vehicle $\mathrm{kmstravel}(\mathrm{VKT})$ or the amount of travel. Hence in the long run, apart from reducing emissions per $\mathrm{km}$ in individual vehicles, efforts must be made to reduce the demand for motorized transport.

Emissions per $\mathrm{km}$ (in grams of pollutants per $\mathrm{km}$ ) is affected by a variety of parameters: Engine and vehicle technology, fuel characteristics, fuel efficiency, maintenance of the vehicle, speed, congestion on the road, driving etc. generally better vehicle technology, better fuel quality, improving maintenance and inspection, scraping old vehicles, better driving, reducing congestion on roads etc; can improve fuel efficiency and reduce pollutant emissions

Vehicular pollution in Chennai city- An overview

Recent reports on Chennai city's pollution due to impact of vehicular pollution by state and central pollution control board, Environmentalists, scientists, reports by private environmental enthusiasts, etc reveal the following.

The city's coastline is a blessing not only does the sea breeze disperse the heat, it also carries away pollutants. But the day is not far when Chennai will overtake Delhi in pollution levels, warns a study of 14 cities by the Centre for Science and Environment(CSE).( Article published in "The Hindu News paper dated 02.09.18)
Averaging across its three monitoring stations, Chennai had the highest proportion of severe days( 17.7 percent $)$ and a third of all days were either severe, very poor or poor quality. The average AQI value for the last six months for these cities was also higher than Delhi's(A report published in The Hindu news paper dated 15.07.2013 by Rukmani and Samarth Bansal under the title " The quality of air you breath in Chennai is worse than in Delhi/)

Not at all like other super urban communities, Chennai speaks to an alternate contamination challenge. Its yearly normal contaminations however lower than other uber urban communities - still fluctuate between moderate to basic. Without ocean breeze in this beach front city, the pinnacles could have been more regrettable.

Reports says that throughout the most recent two decades, portion of transport and train has dropped radically. The portion of individual vehicle trips has expanded.

A quick acceleration in levels of different toxins has been seen:

PM 10 levels have expanded from 32 microgram for every cu $\mathrm{m}$ in 2007 to 94 microgram for every cu $\mathrm{m}$ in 2011 ( a 193 percent hop) and 150 microgram for each cu $\mathrm{m}$ in 2018(368 percent) - expanding 33percent per year

NOx level rose from 9micrograme per cu $\mathrm{m}$ in 2007 to 24micrograme per cu $\mathrm{m}$ in 2011 - an expansion of 166 percent at 60 percent a year which is principally due increment in utilizing of vehicles

A concentrate did by researchers of college of Berkeley distributed in Environmental Science and Technology in 2012 demonstrates that the introduction to vehicular fumes(in terms of populace weighted consumption part, or the grams of vehicle contamination breathed in per grams of vehicle contamination radiated ) in Chennai (72) is one of the most elevated in urban communities contemplated in India-third after Kolkatta(150) and Delhi(100)

Increasing urbanization, industrialization and motorization result in more energy demand which generally leads to higher emissions of air pollutants. The Indian population is fast urbanizing. Out of about one billion population in 2000 , the urban population was around 300 million,(30\%) 410 million in $2010(36 \%)$ and it is expected to reach $44 \%$ by 2020.Liberalization and globalization apart from increasing industrialization has increased the personal incomes which resulted in exponential growth in motorization.[22]-[25]

Among six mega cities and eight metropolitan cities where the study was conducted by centre for Environment and Science, New Delhi, Chennai was found to have the highest average trip length of cars, which means that people who travelled by cars covered long distances.

Personal vehicles dominate in terms of daily distance travelled in Chennai and other cities. In Chennai where the absolute number of registered vehicles is already large, the average annual growth rate of vehicles between 2006 and 2016 was a whopping $12.8 \%$. 
With all these vehicles on the roads, Chennai's PM10 concentration is way above the permissible level of 60 micro grams/cubic metre. Every time we make a trip by personal transport, we contribute two to five times more emissions as opposed to making a trip by public transport. Pollution load per travel trip per year from personal vehicles is significantly higher than that of public transport trip across cities. Though nitrogen oxide levels have seen a spike, they remain within permissible limits, The danger with increasing nitrogen oxide levels is that the cumulative effect of NOx for all travel trips is enormous.[26]-34]

It also indicates that in cities with a rising volume of travel, if personal vehicle trips are substituted with public transport trips, transport related emissions and energy consumptions can decline substantially.

With its higher trip rate, trip lengths and low modal share of public transport, Chennai's emissions per trip are higher than Delhi. What this means, as the population increases in Chennai and it spreads further, is that levels of air pollution, carbon emissions and energy consumption will get far worse, leaving even Delhi behind, the report said.

Hence a fact finding survey has been conducted to assess the pollution stress in various locations of the Chennai city covering Residential, Industrial and Commercial area

Air quality monitoring

In India, $\mathrm{CPCB}$ implements the national ambient air quality monitoring program (NAMP) through a network comprising 544 operating ambient air quality stations covering 224 cities/towns in 26 states and 5 union territories of the country.

Online monitoring network(continuous sampling)

These are robotized air quality checking stations which record constant hourly, month to month or every year arrived at the midpoint of information and parameters like PM10,PM2.5,NOx,SOx,CO and O3 are observed continuously.Data from these stations are accessible nearly progressively. In this way such systems are generally reasonable for calculation of AQI sub-records as data on AQI can be created progressively. For AQI to be progressively helpful and powerful there is a need to set up increasingly internet checking stations for nonstop and simple accessibility of air quality information for calculation of AQI for progressively Indian urban areas.

The sub lists for mechanical toxins at observing area are determined utilizing its 24 hours hourly normal focus esteem ( 8 hourly if there should arise an occurrence of $\mathrm{CO}$ and $\mathrm{O} 3$ ) and wellbeing breakpoint fixation run. The most noticeably terrible sub-list is the AQI for that area.

In general $\mathrm{AQI}$ at a specific station is determined just if pieces of information are accessible for least three toxins out of which one ought to fundamentally be PM2,5/PM10 and some other two contaminations. So also at least 16 hours information is viewed as fundamental for figuring sub list.

\section{Manual SAMPLing}

The manual stations include generally discontinuous air quality information assortment, in this way such stations are not reasonable for AQI figuring especially for its brisk dispersal. In India a large portion of the air quality observing stations under NAMP is physically worked stations and just three criteria poisons viz PM10,Sox \&NOx are estimated, at certain stations $\mathrm{PM} 2,5$ and $\mathrm{Pb}$ are additionally estimated. The observing recurrence is two times every week. Such manual systems are not reasonable for figuring AQI, as accessibility of observed information could have a slack of 1-3 days and a few times not accessible by any means. Anyway a few endeavors are required to utilize data in some beneficial way i.e investigate related examinations/ventures.

Calculation of air quality index (AQI) under manual sampling

In Manual stations, the sub-indices for pollutants are determined and disseminated even if datas are inadequate for determining AQI. The individual pollutant wise sub-index will provide air quality stations for that pollutant. Using the formula given below AQI can be found out under manual sampling.

For manual monitoring stations, an AQI calculator is developed wherein data can be fed manually to get AQI value.

$\boldsymbol{I} \mathrm{p}=[\{\boldsymbol{I H} \boldsymbol{i}-\boldsymbol{I L o} / \mathrm{B} \boldsymbol{H i}-\mathrm{BLo}\} \mathbf{x}(\mathrm{Cp}-\mathrm{B} L o)]+\boldsymbol{I L o}$

Where

Ip = Sub Index for a given pollutant

IHi = AQI value corresponding to $\mathrm{Bm}$

ILo = AQI value corresponding to Bw

$\mathrm{BHi}=$ Break point concentration greater or equal to given concentration $(\mathrm{Cp})$

$\mathrm{BLo}=$ Break point concentration smaller or equal to given concentration $(\mathrm{Cp})$

$\mathrm{Cp}=$ Pollutant concentration

$\mathrm{AQI}=\operatorname{Max}(\mathrm{Ip})($ where $\mathrm{p}=1.2 .3 \ldots \mathrm{n})$ whereas $\mathrm{n}$ denotes no. of pollutants)

Conducting fact finding survey to evaluate the status of air pollution in and around Chennai city

Air pollutants like Particulate matter ( PM2.5 \&PM10),Sox and NOx were measured at the following locations of Chennai city.

Table 1 : Proposed locations of survey at Chennai city

\begin{tabular}{|c|c|c|}
\hline Sl.No. & CATEGORY & PLACE \\
\hline 1 & RESIDENTIAL AREA & ANNA NAGAR \\
\hline 2 & COMMERCIAL AREA & T.NAGAR \\
\hline 3 & INDUSTRIAL AREA & MANALI \\
\hline
\end{tabular}

\section{RESULTS AND DISCUSSION}

AQI of PM2.5,PM10,SO2 and $\mathrm{NO} 2$ have been arrived at the three stations one at Chennai- Anna Nagar(Residential Area),second one at Chennai -Manali(Industrial Area) and third one at Chennai - T.Nagar (Commercial/Traffic Area)

The pollution level and calculated Air Quality Index for the above three stations are given in Table 3.4 and 5 . 


\begin{tabular}{|c|c|c|c|c|c|c|c|c|c|c|}
\hline Pollutant & $\mathrm{SO}_{2}$ & $\mathrm{NO}_{2}$ & $\mathrm{PM}_{25}$ & $\mathrm{PM}_{10}$ & \multicolumn{2}{|c|}{0} & \multicolumn{2}{|c|}{$\mathrm{CO}\left(\mathrm{mgm}^{3}\right)$} & Ph & $\mathrm{NH}_{3}$ \\
\hline Averaging time (hr) & 24 & 24 & 24 & 24 & 1 & 8 & 1 & 8 & 24 & 24 \\
\hline Standard & 80 & 80 & 60 & 100 & 180 & 100 & 4 & 2 & 1 & 400 \\
\hline
\end{tabular}

Note: All units are in ug $\mathrm{m}^{3} \mathrm{unless}$ mentioned othervise. Source: CPCB.

\begin{tabular}{|c|c|c|c|c|c|c|c|c|c|c|c|}
\hline \multirow[t]{2}{*}{$S$ SNe } & \multirow[t]{2}{*}{ SEASON } & \multirow{2}{*}{$\begin{array}{l}\text { SAIPLING } \\
\text { DATE }\end{array}$} & \multicolumn{4}{|c|}{ 24. Hoursaverags in ing" } & \multicolumn{4}{|c|}{ SUBIIDEXX } & \multirow[t]{2}{*}{ AQ! } \\
\hline & & & PMLS & PMIID & 802 & 102 & PMLL. & PMIII & 802 & . 02 & \\
\hline$T$ & 1.100NSOON & 01.11 .18 & 35 & 1.26 & 9 & 114 & 35 & 126 & I! & 18 & 1.26 \\
\hline$?$ & & 08.111 .18 & 40 & 105 & T! & 75 & 40 & 705 & 75 & 19 & 705 \\
\hline 3 & & 15.1118 & 4.5 & 120 & 13.8 & 20.8 & 45 & 120 & T1 & 26 & 1.20 \\
\hline 4 & & 21.11 .18 & 24 & T!1. & 10.7 & 23.3 & 24 & III & 13 & 29 & $7 ! 2$ \\
\hline$i$ & & 25.11 .18 & 32 & $75 \%$ & III & 224 & 32 & 755 & 15 & 28 & 75 \\
\hline 6 & \begin{tabular}{|l|} 
POSI \\
NONSOON \\
\end{tabular} & 02.12 .18 & 46 & 100 & 159 & 24.6 & 46 & 100 & 20 & $3 !$ & 700 \\
\hline 7 & & 08.12 .18 & 34 & 74 & 16.5 & 269 & 34 & 74 & 21 & 34 & 74 \\
\hline 8 & & 15.12 .18 & 23 & 45 & 16.8 & 27.6 & 23 & 45 & 21 & 35 & 4.5 \\
\hline 9 & & 21.1218 & 25 & 39 & 1.5 & 24.9 & 25 & 39 & 18 & 3! & 39 \\
\hline 10 & & 28.12 .18 & 44 & 1.47 & !1 & 21 & 44 & 147 & 15 & 34 & T.7) \\
\hline III & & 01.01 .19 & 38 & 1.24 & It & 33 & 38 & 124 & 18 & 4! & 7.24 \\
\hline 12 & WNIER & 06.0119 & 38 & 100 & 9 & 21 & 38 & 100 & II & 26 & 100 \\
\hline 13 & & 14.01 .19 & 3 & 1.45 & 13 & 30 & 32 & 1.43 & 16 & 38 & 1.43 \\
\hline 1.4 & & 19.0119 & 34 & 95 & II & 25 & 34 & 95 & 14 & $3 !$ & 95 \\
\hline 15 & & 26.0119 & 46 & 1123 & 14 & 33 & 46 & 123 & 18 & 4! & 1.23 \\
\hline 16 & & 03.0219 & $\pi$ & 95 & II! & 25 & 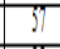 & 95 & 1.4 & 3! & 95 \\
\hline$\Pi$ & & 09.02 .19 & 39 & 107 & 1.4 & 29 & 39 & 107 & 18 & 36 & 707 \\
\hline 18 & & 17.02 .19 & 47 & 127 & 1.4 .4 & 15.6 & 4 & 127 & 18 & 20 & T.27 \\
\hline 19 & & 220.0219 & 44 & 745 & 11 & I.!. & 44 & 1.55 & 15 & 19 & T.4. \\
\hline 20 & & 28.02 .19 & 38 & 137 & 9 & 14 & 38 & 137 & II & 18 & 137 \\
\hline
\end{tabular}

AQI of the all the stations fall under Good,Satisfactory and Moderate category. Majority of the days the AQI fall under satisfactory and moderate category.

From the AQI of the above three stations, it is observed that responsible pollutant is PM2.5 and PM10.The other pollutants i.e SO2 and NO2 are under good category for all stations for all days.

AQI at Chennai - Anna Nagar varies from 45 to 155.Majority of the days AQI falls in Satisfactory and Moderate category,Vehicle pollution in and around Anna Nagar area is the main cause for increase in PM10 level.

Table 4 Ambient Air Quality Report at Chennai-Manali(Industrial Area)

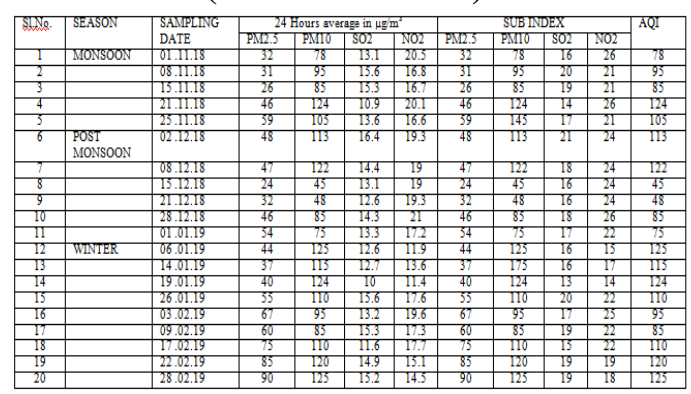

Table 5 Ambient Air Quality Report at Chennai-T.Nagar(Commercial/Traffic Area)

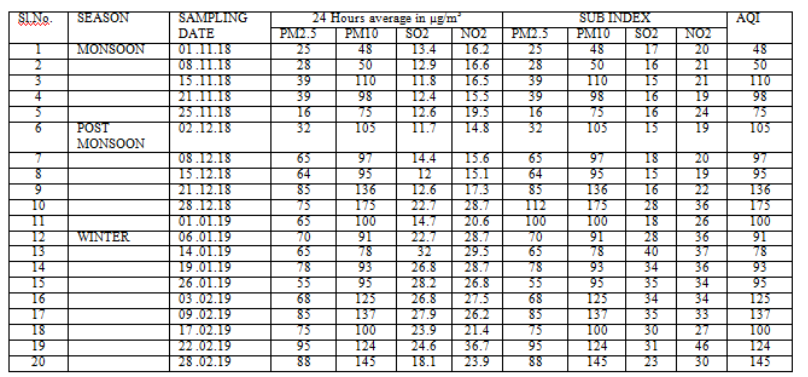

AQI at Chennai- Manali varies from 45 to 125. Majority of the days AQI falls in Satisfactory and Moderate category,Vehicle pollution is the main cause for increase in PM10 level.Mostly heavy vehicles are plying on the road and less no. of two wheelers and cars when compared to Anna Nagar and T,Nagar

AQI at Chennai- T.Nagar varies from 48 to 175. Majority of the days AQI falls in Satisfactory and Moderate/Poor category,It is a Commercial area and Vehicle movement is the main cause for increase in PM10 level.

\section{Vulnerability Analysis}

The most exceedingly awful thing about vehicular contamination is that it can't be dodged as the emanations are discharged at the close ground level where we relax. Contamination from vehicles gets reflected in expanded mortality and dreariness and is uncovered through side effects like hack, migraine, queasiness, aggravation of eyes, different bronchial issues and perceivability. The contamination from vehicles are because of releases like $\mathrm{CO}$, unburned $\mathrm{HC}, \mathrm{Pb}$ mixes, NOx, sediment suspended particulate issue (SPM) and aldehydes, among others, basically from the tail channels.

\section{Ingredients of vehicular pollution}

The key pollutants which are emitted from these motor vehicles in the atmosphere cause serious health impacts. The pollutants wise health effects are summarized in the Table. 6 An ongoing report that in Delhi one out of each 10 younger students experiences asthma that is compounding because of vehicular contamination.

As per the World Health Organization (WHO), 4 to $8 \%$ of passings that happen every year on the planet are identified with air contamination and of its constituents, the WHO has recognized SPM as the most vile as far as its impact on wellbeing.

The SPM isn't homogeneous. It has various constituents. Thus, it is estimated and portrayed in different manners: (I) TSP (Total suspended particulates) with molecule distances across $<50-100 \mathrm{~m}$ is the division tested with high-volume samplers. (ii) PM10: Inhalable particles having a width $<10 \mathrm{~m}$ infiltrates through the nose, by relaxing. (iii) Thoracic particles: are around equivalent to PM10 particles. (iv) PM2.5: 'Fine portion' with a breadth $<2.5 \mathrm{~m}$ enters to the lungs; and (v) Black smoke: 
a proportion of the darkness of a molecule test gives a relative incentive for the

sediment substance of the example. Because of their high wellbeing harming potential ongoing investigations have begun giving more consideration to PM10 and PM2.5 particles.

\section{Conclusion}

Data collected from the survey conducted (i.e AQI of Chennai city) reveals that PM10 is the main contributor for higher value of index. Sox and NOx are well within the NAAQ standards for 24 hours. The higher value of PM10 is mainly due to vehicular pollution because transport is a major sector that contributes to air pollution, especially in urban areas.

\section{REFERENCES}

1. Iyappan L., Dayakar P., Identification of landslide prone zone for coonoortalukusing spatial technology, International Journal of Applied Engineering Research,V-9,I-22,PP-5724-5732,Y-2014.

2. Kumar J., Sathish Kumar K., Dayakar P.,Effect of microsilica on high strength concrete, International Journal of Applied Engineering Research,V-9,I-22,PP-5427-5432,Y-2014.

3. Dayakar P., Vijay Ruthrapathi G., Prakesh J., Management of bio-medical waste, International Journal of Applied Engineering Research,V-9,I-22,PP-5518-5526,Y-2014

4. Swaminathan N., Dayakar P., Resource optimization in construction project, International Journal of Applied Engineering Research,V-9,I-22,PP-5546-5551,Y-2014.

5. Venkat Raman K., Dayakar P., Raju K.V.B.,An experimental study on effect of cone diameters in penetration test on sandy soil, International Journal of Civil Engineering and Technology,V-8,I-8,PP-1581-1588,Y-2017.

6. Saritha B., Chockalingam M.P.,Photodradation of malachite green DYE using TIO2/activated carbon composite,International Journal of Civil Engineering and Technology,V-8,I-8,PP-156-163,Y-2017

7. Shendge R.B., Chockalingam M.P., Saritha B., Ambica A.,Swat modelling for sediment yield: A case study of Ujjani reservoir in Maharashtra, India,International Journal of Civil Engineering and Technology,V-9,I-1,PP-245-252,Y-2018

8. Chockalingam M.P., Balamurgan V.,Modernisation of an existing urban road-sector in Chennai, a case study report,International Journal of Civil Engineering and Technology,V-8,I-8,PP-1457-1467,Y-2017

9. Saritha B., Chockalingam M.P.,Adsorption study on removal of basic dye by modified coconut shell adsorbent, International Journal of Civil Engineering and Technology,V-8,I-8,PP-1370-1374,Y-2017

10. Saritha B., Chockalingam M.P.,Adsorptive removal of heavy metal chromium from aqueous medium using modified natural adsorbent,International Journal of Civil Engineering and Technology,V-8,I-8,PP-1382-1387,Y-2017

11. Chockalingam M.P., Palanivelraja S.,Retrospective analysis of a theoretical model used for forecasting future air quality near the north Chennai thermal power plant,International Journal of Civil Engineering and Technology,V-8,I-8,PP-1457-1467,Y-2017

12. Saritha B., Chockalingam M.P.,Photodegradation of methylene blue dye in aqueous medium by $\mathrm{Fe}-\mathrm{AC} / \mathrm{TiO} 2$ Composite, Nature Environment and Pollution Technology,V-17,I-4,PP-1259-1265,Y-2018

13. Shendge R.B., Chockalingam M.P., Kaviya B., Ambica A.,Estimates of potential evapotranspiration rates by three methods in upper Bhima Basin, In Maharashtra, India,International Journal of Civil Engineering and Technology,V-9,I-2,PP-475-480,Y-2018

14. Shendge R.B., Chockalingam M.P.,The soil and water assessment tool for Ujjani Reservoir,International Journal of Mechanical Engineering and Technology,V-9,I-2,PP-354-359,Y-2018

15. Shendge R.B., Chockalingam M.P.,A review on soil and water assessment tool,International Journal of Mechanical Engineering and Technology,V-9,I-2,PP-347-353,Y-2018

16. Sachithanandam P., Meikandaan T.P., Srividya T.,Steel framed multi storey residential building analysis and design,International Journal of Applied Engineering Research,V-9,I-22,PP-5527-5529,Y-2014
17. Meikandaan T.P., Ramachandra Murthy A.,Study of damaged RC beams repaired by bonding of CFRP laminates,International Journal of Civil Engineering and Technology,V-8,I-2,PP-470-486,Y-2017

18. Meikandaan T.P., Ramachandra Murthy A.,Retrofittng of reinforced concrete beams using GFRP overlays,International Journal of Civil Engineering and Technology,V-8,I-2,PP-423-439,Y-2017

19. Meikandaan T.P., Ramachandra Murthy A.,Flexural behaviour of RC beam wrapped with GFRP sheets,International Journal of Civil Engineering and Technology,V-8,I-2,PP-452-469,Y-2017

20. Meikandaan T.P., Murthy A.R.,Experimental study on strengthening of rc beams using glass Fiber,International Journal of Civil Engineering and Technology,V-9,I-11,PP-959-965,Y-2018

21. Meikandaan T.P., Hemapriya M.,Use of glass FRP sheets as external flexural reinforcement in RCC Beam,International Journal of Civil Engineering and Technology,V-8,I-8,PP-1485-1501,Y-2017

22. Saraswathy R., Saritha B.,Planning of integrated satellite township at Thirumazhisai,International Journal of Applied Engineering Research,V-9,I-22,PP-5558-5560,Y-2014

23. Saritha B., Ilayaraja K., Eqyaabal Z.,Geo textiles and geo synthetics for soil reinforcement,International Journal of Applied Engineering Research,V-9,I-22,PP-5533-5536,Y-2014

24. Ambica A., Saritha B., Changring G., Singh N B., Rajen M., Salman Md.,Analysis of groundwater quality in and around Tambaram taluk, Kancheepuram district,International Journal of Civil Engineering and Technology,V-8,I-8,PP-1362-1369,Y-2017

25. Arunya A., Sarayu K., Ramachandra Murthy A., Iyer N.R.,Enhancement of durability properties of bioconcrete incorporated with nano silica,International Journal of Civil Engineering and Technology,V-8,I-8,PP-1388-1394,Y-2017

26. Ilayaraja K., Krishnamurthy R.R., Jayaprakash M., Velmurugan P.M., Muthuraj S.,Characterization of the 26 December 2004 tsunami deposits in Andaman Islands (Bay of Bengal, India),Environmental Earth Sciences, V-66,I-8,PP-2459-2476,Y-2012

27. Ilayaraja K.,Morphometric parameters of micro watershed in Paravanar sub-basin, Cuddalore District,International Journal of Civil Engineering and Technology,V-8,I-8,PP-1444-1449,Y-2017

28. Ilayaraja K., Singh R.K., Rana N., Chauhan R., Sutradhar N.,Site suitability assessment for residential areas in south Chennai region using remote sensing and GIS techniques, International Journal of Civil Engineering and Technology,V-8,I-8,PP-1468-1475,Y-2017

29. Ilayaraja K., Reza W., Kumar V., Paul S., Chowdhary R.,Estimation of land surface temperature of Chennai metropolitan area using Landsat images,International Journal of Civil Engineering and Technology,V-8,I-8,PP-1450-1456,Y-2017

30. Chitra R.,Experimental study on beam using steel fiber and latex,International Journal of Civil Engineering and Technology,V-8,I-8,PP-1395-1403,Y-2017

31. Chitra R.,Analysis of traffic and management at Kovilambakkam intersection,International Journal of Civil Engineering and Technology,V-8,I-8,PP-1433-1443,Y-2017

32. Aswathy M.,Experimental study on light weight foamed concrete,International Journal of Civil Engineering and Technology,V-8,I-8,PP-1404-1412,Y-2017

33. Aswathy M.,Wastewater treatment using constructed wetland with water lettuce (Eichornia Crasipies),International Journal of Civil Engineering and Technology,V-8,I-8,PP-1413-1421,Y-2017

34. Kiruthiga K., Anandh K.S., Gunasekaran K, Assessment of influencing factors on improving effectiveness and productivity of construction engineers, 2015, International Journal of Applied Engineering Research, V - 10,I -17,p -13849-13854.

\section{AUTHORS PROFILE}

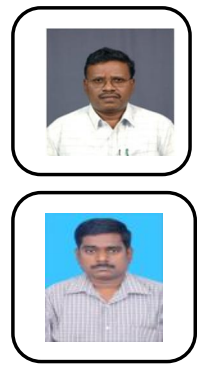

Dr.A.Mani, Professor, Department Of Civil Engineering,,Bharath Institution Of Higher Education And Research,TamilNadu, India

G.Kannan M.Tech Environmental Engineering, „Bharath Institution Of Higher Education And Research,TamilNadu, India 